\title{
GESTÃO DE PROJETOS NO TERCEIRO SETOR ANGOLANO: UMA ANÁLISE PARA 6 ONGS
}

\author{
PROJECT MANAGEMENT IN THE ANGOLAN THIRD SECTOR: AN ANALYSIS FOR \\ $6 \mathrm{NGOS}$
}

\author{
Raíza Fernandes Aragão \\ Mestranda em Políticas Públicas \\ Instituto Universitário de Lisboa - Iscte. \\ Maputo - Moçambique. \\ raiza_aragao@hotmail.com \\ Danielle Evelyn de Carvalho \\ Doutoranda em Economia \\ Universidade Federal de Minas Gerais - UFMG \\ Belo Horizonte, MG - Brasil. \\ danielle-evelyn@hotmail.com
}

\begin{abstract}
Resumo
Buscar compreender como Organizações Não Governamentais angolanas gerenciam seus projetos e como a aplicação das boas práticas em gestão pode impulsionar a atuação dessas é fundamental para se alcançar um maior nível de profissionalização e, consequentemente, uma melhor resposta social dessas organizações. O presente trabalho tem por objetivo compreender quais aspectos da gestão de projetos preconizada pelo PMI são incorporados no dia a dia de projetos desenvolvidos por ONGs angolanas. O delineamento da pesquisa fundamentou-se, sobretudo, no estudo de caso, utilizando a análise documental, entrevista e observação, em que se apoiou em uma pesquisa qualitativa/exploratória. As entrevistas foram guiadas e aplicadas por meio de questionário online, enviado via e-mail, para membros de seis ONGs angolanas que desenvolvem projetos em diversos setores sociais na cidade de Luanda. Como resultado, foi analisada a adoção das práticas sugeridas pelo PMBOK no que tange ao Gerenciamento do Escopo, do Tempo, dos Custos e das Partes Interessadas. Observou-se um cenário promissor e receptivo às boas práticas em Gestão de Projetos, mas com uma realidade de aplicação ainda inaugural em boa parte das entidades. Um dos principais desafios apontados pelos entrevistados das ONGs é na captação de recursos, seguida pela falta de pessoal qualificado para gerir os projetos e número reduzido de equipe. Também foram encontradas dificuldades em relação ao gerenciamento dos stakeholders, notando-se uma fraca aplicação da gestão de projetos no que toca à prestação de contas para as partes interessadas, além das divergências entre funcionários em relação à situação de pessoas contratadas pelas ONGs.
\end{abstract}

Palavras-chave: Angola. Organizações da sociedade civil. Projetos sociais. Gestão de projetos.

\section{Abstract}

Seeking to understand how Angolan Non-Governmental Organizations manage their projects and how the application of good management practices can boost their performance is essential to achieve a higher level of professionalization and, consequently, a better social response for these associations. The present work aims to understand which aspects of project management recommended by PMI are incorporated into the day-to-day projects developed by Angolan NGOs. The research design was mainly based on the case study, using document analysis, interview and observation, in which it was supported by a qualitative/exploratory research. The communications were guided and applied through an online questionnaire, sent via e-mail, to six Angolan NGOs that develop projects in various social sectors in the city of Luanda. As a result, the adoption of the practices suggested by the PMBOK with regard to Scope, Time, Cost and Stakeholder Management was analyzed. A promising and receptive scenario to good practices in Project Management was observed, but with a reality of application that is still inaugural in most of the entities. One of the main challenges identified by NGO respondents is in fundraising, followed by the lack of qualified personnel to manage the projects and a reduced number of staff. Difficulties were also encountered in relation to stakeholder management, with a weak solution for project management in terms of accountability for related parties, in addition to differences between employees in relation to the situation of people hired by NGOs.

Keywords: Angola. Civil society organizations. Social projects. Project management.

Cite como

American Psychological Association (APA)

Aragão, R. F., \& de Carvalho, D. E. (2021, set./dez.). Gestão de projetos no terceiro setor angolano: uma análise para 6 ONGS. Revista de Gestão e Projetos (GeP), 12(3), 1-35. https://doi.org/10.5585/gep.v12i3.19549. 


\section{Introdução}

A Angola é um país localizado na África Austral que conquistou a independência apenas em 1975 e enfrentou longos 27 anos de guerra que perduraram até 2002. Constatou-se um significativo crescimento econômico após o fim do conflito armado, com o aumento do Produto Interno Bruto (PIB) que alcançou uma média anual de crescimento de $12,6 \%$ entre 2006 e 2010 , posicionando Angola como um país de renda média-baixa (Ministério da Economia e Planeamento, 2019). Porém esse fenômeno não representou significativo desenvolvimento social, distribuição de renda ou melhora nas condições de vida da população em geral.

Foi nesse contexto de vulnerabilidade extrema e baixos indicadores sociais que Organizações Multilaterais como as Nações Unidas, Instituições Financeiras Internacionais, Organizações Não Governamentais (ONGs) internacionais, bem como Organizações da Sociedade Civil local, ainda em meados de 1990, passaram a exercer um papel primordial na concretização de direitos da população angolana. Assim, como forma de substituir a ausência estatal, Organizações do Terceiro Setor vem desenvolvendo projetos nas mais variadas esferas sociais. Tal característica é resultado de um quadro de ineficiência/ausência de Políticas Públicas, que oferece ensejo a um campo de trabalho comandado por organizações sociais, proliferando-se rapidamente e expandindo suas ações na tentativa de reduzir as desigualdades sociais (Ribeiro, 2010).

Atualmente, diversas ONGs atuam em todo o território angolano, financiadas por Organismos e Empresas internacionais, ou Governo e empresas locais, bem como por particulares. Essas Instituições trabalham ativamente na busca pelo bem-estar social da população, em especial, diante do contexto contemporâneo de forte recessão econômica, crise humanitária, dada a vinda de refugiados da República Democrática do Congo, severa seca ao sul do país e surto de poliomielite.

Portanto, o trabalho das Organizações da Sociedade Civil tem sido essencial para o processo de redemocratização angolana no pósguerra. Pereira et al. (2013) salienta que a heterogeneidade dos desafios sociais presentes em países subdesenvolvidos e em desenvolvimento requer, como outrora citado, a mobilização dos mais variados atores sociais: primeiro, 
segundo e terceiro setor trabalhando conjuntamente na construção de uma sociedade mais justa e igualitária. Em consonância com a linha de pensamento expressa pelo autor supracitado, o Plano de Desenvolvimento Nacional 20182021 elenca como um de seus objetivos a multiplicação dos atores sociais, buscando fomentar e acolher as iniciativas da sociedade civil e de organizações do Terceiro Setor, estimulando, assim, o exercício da cidadania e propiciando o comprometimento dos demais setores, além do primeiro setor, no desenvolvimento de condições mínimas para o alcance do tão sonhado bem-estar social (Ministério da Economia e Planeamento, 2018).

Contudo, o Terceiro Setor ainda enfrenta sérios obstáculos que permeiam suas atividades, em especial, no que diz respeito à administração, que, por vezes, tem como marca o amadorismo, grande fator de insucesso de projetos organizacionais (Pereira et al. 2013). Uma das explicações para esse cenário é que a multiplicação de organizações sociais e a expansão de seus projetos não foram acompanhadas por uma produção científica na área que embasasse a atuação dessas instituições (Ribeiro, 2010). De acordo com Silva (2017), o processo de desenvolvimento da gestão de projetos exige não apenas pessoas e técnicas qualificadas, mas também ferramentas que sejam adequadas para a gestão. No entanto, essa gestão mais "profissional" no terceiro setor ainda está se estruturando.

Existe uma crescente busca por recursos financeiros em relação a essas organizações, exigindo uma adequação à realidade do mercado, em busca de aperfeiçoamento e profissionalização. Uma postura cada vez mais profissional das organizações é exigida para garantir uma liberação de fundos e recursos financeiros adequada e, como consequência, a auto sustentabilidade dessas instituições. (Oliveira, Ross \& Altimeyer, 2005; Silva, 2017). Ademais, o Terceiro Setor possui nuanças específicas que tornam a gestão um desafio ainda maior, tendo em vista o abrangente campo de atuação e as limitações de ordem recursais nas áreas materiais, financeiras e humanas (Pereira et al. 2013). Por isso, a Gestão de Projetos é tema sensível no que tange o terceiro setor, posto que essas instituições trabalham diariamente implementando projetos de alto valor social. Assim, entender como ONGs angolanas gerenciam seus projetos, analisando se aplicam algumas das boas 
práticas preconizadas pelo PMI, é essencial para o aperfeiçoamento da atuação dessas organizações.

Para tal efeito, estudou-se seis ONG que atuam na província de Luanda e que desenvolvem projetos em relevantes setores sociais. Em geral, as áreas de atuação das Organizações se cruzam, tanto no que tange ao desenvolvimento de projetos educacionais, como em relação ao público-alvo, que é majoritariamente de crianças e jovens. No mais, todas estão situadas na Província de Luanda e são Organizações de pequeno ou médio porte. No trabalho em curso, utilizou-se a definição clássica de Projetos como sendo todo e qualquer empreendimento periódico com um conjunto pré-definido de resultados esperados, realizados dentro de um cronograma e a partir de uma previsão de custos (PMI, 2017). A Gestão de projetos, por conseguinte, é o ramo da ciência da Administração que prevê as metodologias, técnicas e melhores práticas, compiladas ao longo dos anos, com vistas a aperfeiçoar/padronizar a administração de projetos (PMI, 2017).

Portanto, buscou-se responder, na ótica da gestão de projetos: Como as ONGs angolanas em estudo gerenciam escopo, custo e tempo de seus projetos?
Existe gerenciamento das partes interessadas? Quais são os principais desafios enfrentados por essas instituições no que tange a gestão de projetos? Diante do exposto, pode-se inferir que, além de atual, o tema apresenta relevância políticaeconômica-social, à proporção que procurou fazer um diagnóstico de como 6 ONGs angolanas gerenciam seus projetos, mostrando quais são os desafios em comum e como a gestão de projetos pode aprimorar o trabalho dessas instituições, diante da relevância social do trabalho desenvolvido por essas e da importância da utilização de ferramentas e técnicas adequadas para uma boa gestão, alinhadas com as práticas de gestão de projetos previstas no PMBOK. Assim sendo, o trabalho proposto poderá ser usado como ferramenta de melhoria na gestão das ONGs pesquisadas, além de fornecer alguma noção sobre o gerenciamento de projetos no terceiro setor angolano, ao menos no que concerne às organizações sociais de pequeno e médio porte.

\section{Referencial teórico}

Esta seção aborda as teorias necessárias para sustentação da pesquisa. 


\subsection{Gestão de projetos e o terceiro setor}

Segundo o Guia PMBOK, a definição de projeto é um esforço temporário com o intuito de criar um produto, serviço ou resultado exclusivo. Devido a sua natureza temporária, os projetos possuem um início e término definidos. Em todos os níveis organizacionais projetos são executados, podendo envolver um único indivíduo ou um grupo, bem como uma única organização ou múltiplas unidades organizacionais de múltiplas organizações (PMI, 2017). Enquanto a gestão de projetos é definida como a aplicação de conhecimentos, habilidades, ferramentas e técnicas em todos os aspectos do projeto, com a finalidade de cumprir os seus requisitos. O gerenciamento de projetos é necessário em qualquer execução de projetos, porque permite que eles sejam feitos de maneira eficaz e eficiente, como resultado da aplicação de práticas apropriadas para cada processo (PMI, 2017). Para o Office of Government Commerce (OGC), o gerenciamento de projetos auxilia no alcance dos objetivos do projeto atingindo o desempenho esperado de tempo, qualidade, custo, escopo, benefícios e riscos (OGC, 2009).

Os processos de gerenciamento de projetos controlam o ciclo de vida do projeto por meio da execução de uma série de atividades, utilizando técnicas e ferramentas de gerenciamento de projetos apropriadas. Embora existam diferentes formas de agrupar processos, o Guia PMBOK divide os processos em cinco categorias, chamadas de Grupos de Processos, que são: iniciação, planejamento, execução, monitoramento e controle e execução. Eles são importantes para definir como serão conduzidas as atividades no ciclo de vida do projeto de modo a atingir todos os requisitos do projeto (PMI, 2017).

Segundo Siqueira, Crispim e Gaspar (2017), o gerenciamento de projetos exerce um importante papel estratégico, além do seu instrumento operacional de adaptação e evolução organizacional. Conforme Vargas (2005, p. 22), “a principal vantagem do gerenciamento é que não é restrito a projetos gigantescos, de alta complexidade e custo. Ele pode ser aplicado em empreendimentos de qualquer complexidade, orçamento e tamanho, em qualquer linha de negócios". Portanto, é possível inferir que o gerenciamento também pode ser feito em instituições que não visam o lucro e possuem natureza social.

Além disso, um gerenciamento de projetos realizado de maneira 
eficiente pode garantir o sucesso de um projeto (Jha \& Iyer, 2006). Tradicionalmente, são analisados os indicadores de prazo, custo, escopo e qualidade do gerenciamento de projetos para definir o sucesso de um projeto. Mais recentemente, também se passou a considerar a realização dos objetivos (PMI, 2017). Já Prado (2016) relaciona o sucesso do gerenciamento de projetos com o nível de maturidade da organização, evidenciando a falta de recursos financeiros e tecnológicos como principal causa nas falhas em projetos. $\mathrm{O}$ autor também mostra outras causas, como a falta de conhecimento em gestão de projeto, a maturidade organizacional, aspectos do ciclo de vida adotado, entre outros. Nesse sentido, com relação à dificuldade de captação de recursos que muitas ONGs possuem, isso não seria o definidor principal do sucesso ou fracasso dos projetos dessas organizações.

Apesar da grande relevância das ONGs para o fortalecimento da busca por soluções dos desafios sociais, a existência dessas organizações por si só não garante que os resultados alcançados sejam os esperados (Nemoto, Silva \& Pinochet, 2018). Hernandez e Cormican (2016) encontraram que há uma má definição no processo de gerenciamento de projeto dessas organizações, além de apresentarem dificuldades de controle, fazendo os projetos se tornarem ineficientes. Conforme os autores, dado que os projetos de inovação social possuem características únicas e são inerentemente diferentes dos projetos de empresas que visam o lucro, essas nuances devem ser consideradas pelo gerente de projetos.

\subsection{Terceiro setor na angola}

Doravante o desenvolvimento econômico constatado no período do pós-guerra, conforme já pontuado na Introdução, Angola enfrenta uma grave crise econômica, que se intensificou nos últimos quatro anos, e fragilizou ainda mais os extratos sociais vulneráveis.

Entre 2011 e 2015, ocorreu uma queda significativa do Produto Interno Bruto [PIB], com uma média de decréscimo de 4,7\%. O crescimento econômico também sofreu um declínio para 2,6\% em 2016, permanecendo negativo em 2017, com um número de 0,1\% (Ministério da Economia e Planeamento, 2019). Um fato que corrobora com as informações supracitadas é que, segundo o Instituto Nacional de Estatística Angolano (2019), a taxa de pobreza nacional passou de 36,6\% em 2015 para 40,6\% 
em 2019, com uma taxa de pobreza rural quase duas vezes maior que a urbana (57,2\% vs. $29,8 \%)$.

Pode-se apontar como uma das principais causas da pobreza em Angola as insuficientes oportunidades de emprego e as discrepâncias regionais no acesso a estruturas sociais e econômicas (Ministério da Economia e Planeamento, 2019). Segundo o INE (2019), a taxa de desemprego atual é de 30,7\%, com 4.150.676 desempregados, sendo a taxa na área urbana de $41,1 \%$ e na área rural de $16,1 \%$. Os níveis de desigualdade no país são considerados significativamente elevados, o que faz com que Angola tenha uma perda de $37 \%$ no índice de desenvolvimento humano (Ministério da Economia e Planeamento, 2019), ocupando a classificação 145 numa lista de 188 países (Programa das Nações Unidas Para o Desenvolvimento [PNUD], 2018). Ademais, segundo o Plano de Desenvolvimento Nacional 2018/2022, a pobreza em Angola ainda está intimamente ligada às consequências do conflito armado, bem como a uma intensa concentração demográfica, especialmente urbana, à dificuldade de acesso à educação e proteção social, e deficitária oferta interna de produtos alimentares
(Ministério da Economia e Planeamento, 2018).

A posição de Angola quanto ao Índice de Desenvolvimento Humano aponta a necessidade inadiável dos mais variados atores sociais e políticos trabalharem em conjunto para proporcionar desenvolvimento nos campos da saúde, educação e melhora no padrão de vida da população em geral (Ministério da Economia e Planeamento, 2019), tendo sido nesse cenário propenso que organizações sociais passaram a atuar intensamente na realidade angolana. Entretanto, conforme já pontuado, a forte atuação de Organizações Não Governamentais não é advento recente. No início da Década de 90 , houve um surgimento crescente dessas organizações dado a assinatura dos Acordos de Paz de Bicesse em 1991, o qual sinalizava, naquele momento, o fim da guerra civil que perdurava desde a independência. Segundo Assis (2015), a passagem de um sistema unipartidarista para um sistema multipartidarista, propiciou uma diversificação de atores políticos e sociais, possibilitando a criação e ampliação do trabalho de Organizações Não Governamentais. Ademais, a necessidade de reestruturação nacional com o fim do conflito armado motivou a 
vinda de organismos e ONGs internacionais, bem como a criação de ONGs locais, estimulados também pela promulgação de legislação específica regulando a criação e funcionamento de Associações Privadas, a Lei 14/91 de 11 de maio.

Contudo, a retomada dos conflitos ainda 1992 tornou o processo de reestruturação inviável, fazendo com que essas organizações trabalhassem com foco predominante em ajudas humanitárias. Esse tipo de ação se expandia aceleradamente à proporção que o conflito armado se acentuava e fragilizava ainda mais a economia e os extratos sociais mais vulneráveis. Os projetos emergenciais desenvolvidos por essas organizações se tornaram um instrumento de garantia de condições mínimas de sobrevivência a várias famílias que tiveram as vidas devastadas pelo retorno da guerra (Assis, 2015).

Com o passar dos anos, e o fim definitivo da guerra em 2002, observouse uma mudança na forma de atuação das ONGs, que ultrapassaram uma fase majoritariamente emergencial e passaram a empreender esforços em projetos de médio e longo prazo nos campos da saúde, educação, alimentação, moradia, planejamento familiar, saúde sexual e muitos outros, associados, por vezes, a uma agenda assistencialista, diante do quadro de desolação provocado pela guerra (Assis, 2015). Fazia-se necessário suprir as mais diversas lacunas sociais, visto que o principal ator político, o Estado, encontrava-se desestruturado e endividado, bem como a economia em colapso. Foi diante desse contexto que as ONGs em estudo iniciaram seus trabalhos e diariamente buscam difundir respostas sociais aos mais diferentes desafios.

\section{Procedimentos metodológicos}

Neste estudo, compreender quais aspectos da gestão de projetos preconizada pelo PMI são incorporados no dia a dia de projetos desenvolvidos por ONGs angolanas se pautou por uma investigação de triangulação. Nesse sentido, os três vértices de investigação que compõem a triangulação deste estudo são: as ONGs angolanas (sujeito), projetos (objeto) e gestão de projetos (fenômeno) (Tuzzo \& Braga, 2016). A seguir, foram definidos os tipos de pesquisa utilizados, os instrumentos de coleta, a população-alvo e os métodos de análise. $\mathrm{O}$ estudo realizado fundamentou-se, sobretudo, em dois tipos de pesquisa. A investigação teórica utilizou a pesquisa bibliográfica e o 
estudo de caso apoiou-se em pesquisa qualitativa/exploratória. Para isto, analisou-se a atuação de ONGs Angolanas que desenvolvem projetos em diversos setores sociais na cidade de Luanda, capital do país. Tratou-se, portanto, de um estudo de caso múltiplo, aquele no qual o pesquisador analisa simultaneamente mais de um caso com o objetivo de compreender fenômeno específico (Gil, 2018).

Os dados do estudo de caso foram coletados por intermédio de múltiplas técnicas, especificamente, análise documental, entrevista e observação. As entrevistas foram guiadas e aplicadas por meio de questionário estruturado online enviado via e-mail, visando uma maior privacidade dos entrevistados e veracidade dos dados. Optou-se por esse meio, devido à dificuldade de se realizar entrevistas presencialmente por causa da pandemia de Covid-19. Ressalta-se que, em duas das ONGs, foi aplicada a técnica de observação na modalidade espontânea e participante, em que uma das autoras colaborou como voluntária em uma das ONGs entre o período de abril de 2019 a 2020 em um projeto de educação profissionalizante e, em outra organização, em ações específicas no Natal de 2018, dia das mães e dia das crianças de 2019. A análise documental também foi realizada somente nessas duas ONGs supracitadas, com a verificação de alguns documentos de projetos que elas desenvolvem, como "portfólios" de visão, missão e valores; e algumas propostas de projetos da organização, planejamento de escopo, custo e cronograma em relação ao projeto principal delas.

Para definição das ONGs em análise, que se trata da população-alvo, buscou-se considerar distintas áreas de atuação social e abordagens - projetos educacionais, de saúde sexual e reprodutiva, prevenção de conflitos e de ajuda aos animais, bem como de pessoas em situação de vulnerabilidade - com vistas a entender o terceiro setor angolano de forma mais ampla, a partir de uma análise amostral. Simultaneamente, optou-se por selecionar ONGs com perfis semelhantes no que diz respeito ao porte, pequeno ou médio, local de atuação Luanda, e ao fato de serem constituídas nos termos das leis angolanas.

Por questões éticas na execução desta pesquisa, as organizações nas quais foram realizados os estudos de caso tiveram suas identificações omitidas, sendo os nomes dessas organizações e quaisquer características que 
permitissem suas identificações pelos leitores. No entanto, a seguir são apresentadas informações gerais sobre as áreas de atuação dessas instituições. A primeira organização trabalha nas áreas de Saúde Sexual e Reprodutiva [SSR], Planejamento familiar, Doenças Sexualmente Transmissíveis [DST's], incluindo a Síndrome da Imunodeficiência Adquirida [AIDS], um dos grandes desafios enfrentados pela sociedade angolana, em parceria com Instituições Internacionais, desenvolvendo palestras e acompanhando adolescentes de um bairro de Luanda, promovendo a liderança de adolescentes e jovens para o desenvolvimento e articulando ações práticas. A segunda Instituição atua com foco em projetos educacionais (educação formal e cursos profissionalizantes) e transformação social em Angola, trabalhando ativamente em uma comunidade com vistas a implementar unidades sociais básicas, proporcionando condições mínimas de vida para a população carente da área. A terceira Organização, assim como a primeira, zela pela Saúde Sexual e Reprodutiva, Gênero, combate à violência baseada no gênero, DST's e AIDS de jovens e adolescentes de ambos os sexos. A quarta Instituição
Filantrópica desenvolve ações com vistas a promover a paz, segurança e estabilidade da sociedade angolana por meio do fortalecimento institucional e prevenção de conflitos. A quinta organização realiza um trabalho com crianças em situação de vulnerabilidade social, prestando assistência tanto na forma de acolhimento, como educacional, com a finalidade de reinseri-las na família e na sociedade. Por fim, a sexta e última entidade desenvolve atividades para o controle de animais de rua, sensibilização da sociedade para a causa, acolhimento, resgate e doações de animais, bem como possui uma extensão de apoio assistencial a pessoas em situação de vulnerabilidade, com distribuição de marmitas diárias.

Cabe ressaltar que todos os participantes expressaram seu consentimento em colaborar com a pesquisa por intermédio de um Termo de Consentimento Livre e Esclarecido no início do questionário. $\mathrm{O}$ texto informava os possíveis riscos aos pesquisados, a isenção da obrigação de responder qualquer pergunta que lhe causasse desconforto, todos os dados da pesquisa e meios de contato com $\mathrm{O}$ entrevistador. Com os dados já coletados, utilizou-se a técnica de 
triangulação na análise dos dados que significa comparar os dados extraídos de uma fonte - a entrevista - com as demais que serviram de base para o trabalho alguns documentos obtidos e a observação presencial de duas ONGs trazendo, assim, maior veracidade aos resultados da investigação (Gil, 2018), no intuito de propiciar mais credibilidade ao estudo de caso. Por fim, os dados foram apresentados por intermédio de instrumentos analíticos, especialmente gráficos, na seção de análise dos resultados.

O questionário foi dividido em dez seções, abordando as áreas de conhecimento mais críticas para a Gestão de Projetos - Gerenciamento do Escopo, do Tempo, dos Custos e das Partes Interessadas - e levando em consideração as peculiaridades do Terceiro Setor. A primeira seção solicitou aos pesquisados dados da Organização e do próprio entrevistado. A segunda tratou dos aspectos formais, a terceira de informações da Equipe, seguidas das seções sobre Conhecimento Geral em Gestão de Projetos, Escopo, Cronograma, Custos, Captação de Recursos e Gestão de Parcerias, Monitoramento e Controle e Aspectos Finais. No total, foram dez entrevistados de seis ONGs e a pesquisa exploratória- descritiva foi realizada entre os dias $2 \overline{7}$ maio e 18 junho de 2020.

Primeiramente, buscou-se conhecer um pouco mais a organização e os pesquisados, com a finalidade de entender qual o perfil dos respondentes e como eles se relacionam com a organização. Indagou-se inicialmente aos pesquisados qual cargo exercem nas respectivas organizações. Entre os entrevistados havia dois Presidentes, dois Diretores, quatro Coordenadores, um Secretário Geral e um Voluntário. Portanto, 9 dos 10 pesquisados exercem algum cargo na administração da entidade, dado relevante que pode impactar o conteúdo das respostas que serão analisadas a seguir, mas que, simultaneamente, pode proporcionar um maior nível de conhecimento da realidade investigada. Sobre o tempo de trabalho na ONG, cinco dos entrevistados estão há dez anos ou mais na entidade, sendo o maior tempo de 20 anos. Os demais relataram atuar na organização entre três e cinco anos.

\section{Resultados e discussão}

Esta seção apresenta os

resultados da pesquisa. 


\subsection{Análise dos resultados}

Após a contextualização do assunto e as considerações sobre a metodologia e métodos utilizados, foram apresentados os resultados advindos da pesquisa. $\mathrm{O}$ primeiro tema a ser abordado foi a organização em si. Quando questionados sobre a situação legal das ONGs, se são formalmente constituídas ou não, com todo o devido registro público em dia, todos os pesquisados responderam positivamente ao questionamento. Ainda na perspectiva de caracterizar as organizações, procurou-se mapear as áreas de atuação dessas. Conforme Figura 1, constatou-se que 8 dos entrevistados relataram que suas Organizações desenvolvem projetos nos segmentos da educação e da saúde, bem como todas as Instituições atuam em pelo menos duas áreas distintas.

\section{Figura 1}

Segmentos de Atuação das Organizações (Mais de uma Opção Pôde ser Marcada)

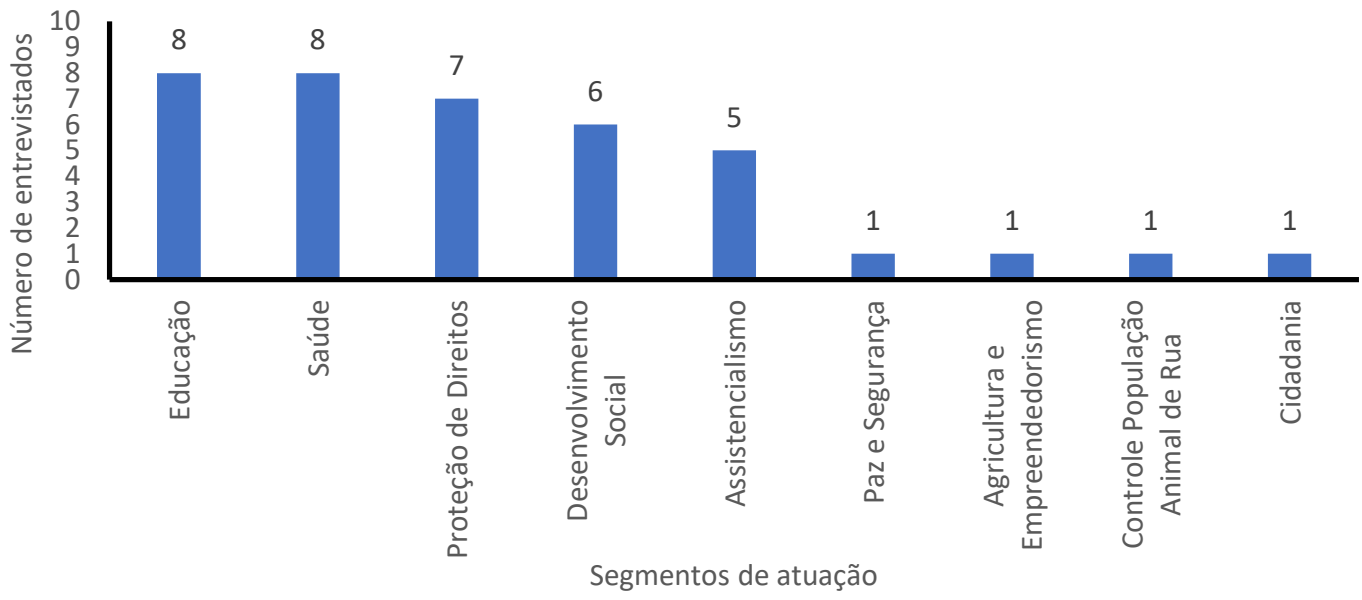

Fonte: Resultados originais da pesquisa.

Relativamente ao tema Governança, todos os pesquisados afirmaram que suas organizações possuem uma estrutura de governança. Apesar disso, quando questionados sobre os órgãos existentes, 9 marcaram que a organização possui uma diretoria, 8 um conselho fiscal e 9 um conselho executivo. A partir da análise das informações, constatou-se que, das seis ONGs, uma delas possui diretoria e conselho fiscal, mas não conta com um conselho executivo, e em outra existe diretoria e conselho executivo, mas sem a presença de um conselho fiscal. Em uma terceira organização, houve um 
ponto de divergência entre as respostas de seus membros. Enquanto um deles marcou positivamente para a existência dos três órgãos em questão, o outro afirmou que a instituição contava apenas com um conselho executivo.

As informações supracitadas se conectam também com a pergunta feita na seção "Captação de Recursos e Gestão de Parcerias", na qual os entrevistados foram questionados sobre a existência de algum tipo de prestação de contas para os stakeholders. Todos responderam que sim, mas apesar da resposta unanimemente positiva, o único tipo de prestação encontrada nas páginas institucionais foi relativo às atividades desenvolvidas. Mesmo em relação às organizações com uma página institucional mais completa e profissional, não se verificou a presença de uma prestação de contas específica, na qual os stakeholders conseguissem acompanhar o orçamento anual de projetos e a destinação dada aos recursos, o que se caracteriza como um obstáculo ao controle e monitoramento dos recursos doados, como analisado porMendonça e Machado Filho (2004). Portanto, a estratégia de prestação de contas precisa ser repensada, tendo em vista que apenas três das seis instituições pesquisadas possuem um site institucional com todās as informações históricas - missão, visão e valores - e das atividades desenvolvidas. As outras três possuem perfil em redes sociais, mas com uma capacidade limitada de informações.

A seção seguinte do questionário tratou da temática equipe. Primeiramente, os entrevistados foram questionados sobre o número de colaboradores no quadro fixo da organização. As respostas apresentaram divergências entre membros de duas instituições. Enquanto um entrevistado afirmou que a ONG contava com 12 membros, o outro da mesma organização afirmou que se tratava apenas de cinco. $\mathrm{Na}$ outra organização em que houve divergência, um dos pesquisados afirmou que a organização tinha um quadro com 20 colaboradores, enquanto o segundo declarou serem apenas 15. Em média, as ONGs em estudo possuem um quadro fixo com 43 membros. Contudo, observando os números separadamente, percebe-se que uma das instituições possui um número elevado em relação às demais, totalizando 150 colaboradores em campo. As outras 5 organizações contam com um número bem mais reduzido de membros, respectivamente, 
$12,14,20,22$ e 40 , pelo que se endossa a informação de serem, em sua maioria, de pequeno ou médio porte.

No que tange à remuneração dos membros, apenas emuma das ONGs nenhum membro é remunerado. Todas as demais possuem ao menos uma parcela de colaboradores assalariados, chegando-se a uma média de aproximadamente $\quad 57 \%$ de pessoas remuneradas por instituição. Na Figura 2 pode-se visualizar a relação entre quantidade de membros e membros remunerados por organização.

\section{Figura 2}

Número de Membros e Pessoal Remunerado

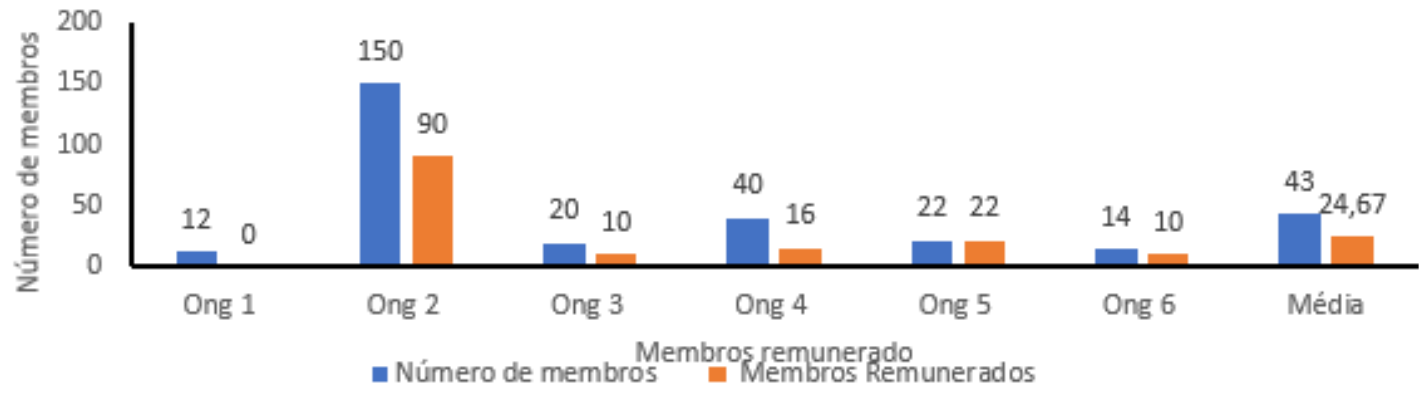

Fonte: Resultados originais da pesquisa.

$\mathrm{Na}$ mesma seção, questionou-se sobre quem conduz no dia a dia a gestão dos projetos da organização. De acordo com as respostas, metade das organizações gerencia seus projetos por intermédio de um gestor de projetos, a outra metade por meio de um diretor. A informação citada, apesar da aparência de pouca relevância, denota que as instituições estão de alguma forma familiarizadas com a linguagem de gestão de projetos e que conhecem, em algum nível, o papel do gestor de projetos ao ponto de terem um membro na equipe exercendo essa função.
Esse dado possui ligação direta com a temática "Conhecimento geral em Gestão de Projetos", que foi abordada na seção seguinte do questionário. Quando questionados sobre o nível de conhecimento em gestão de projetos, 2 dos entrevistados afirmaram serem especialistas, 5 que possuem um nível avançado, outros 2 um nível intermediário e 1 inicial.

Contudo, de acordo com a

Figura 3, quando comparado o número de pessoas com conhecimento em Gestão de Projetos ao número total de membros da entidade, percebeu-se uma 
porcentagem baixa de pessoal com

conhecimento na matéria, sendo a

média de apenas $13 \%$ do quadro oficial de funcionários, pontuando-se que um dos pesquisados deixou em branco o referido campo de resposta.

\section{Figura 3}

Relação Entre o Número de Membros e Membros com Conhecimento em GP

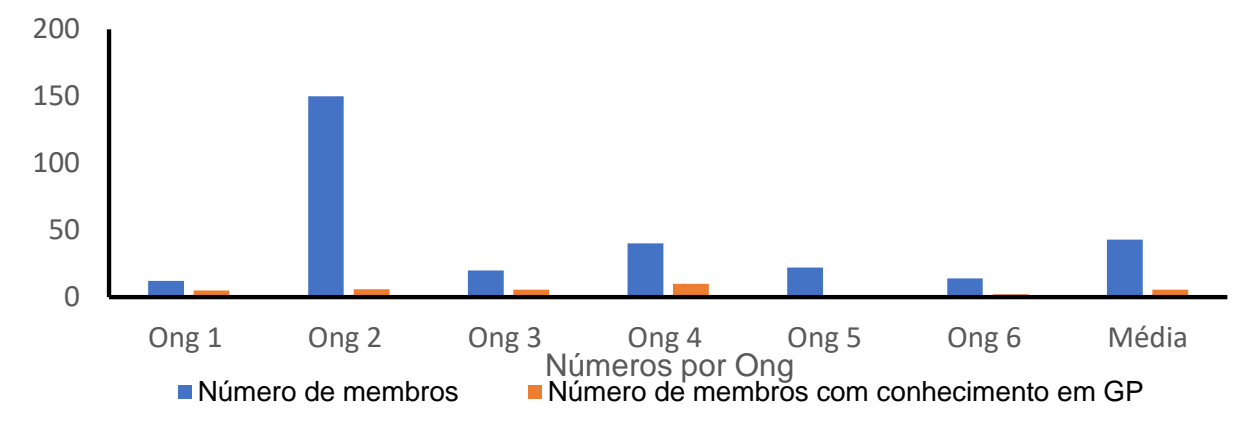

Fonte: Resultados originais da pesquisa.

Analisando as áreas chaves de Gestão de Projetos, na seção "Escopo", os colaboradores foram inicialmente questionados se a Organização elabora algum documento no qual se descrevem os objetivos do projeto, principais entregas, premissas, restrições e exclusões, como uma Especificação do Escopo ou um Termo de Referência. Todos responderam que sim. Todavia, quando perguntados se a entidade elabora algum documento no qual se pode visualizar todas as entregas e o trabalho a ser executado pela equipe do projeto, por exemplo, uma Estrutura Analítica do Projeto (EAP), um dos pesquisados respondeu negativamente, em discordância com a resposta de outros dois membros da mesma organização que haviam respondido sim para a pergunta.

Na seção cronograma, indagouse inicialmente se a organização elabora cronograma para a execução dos projetos, e 9 dos entrevistados responderam que sim. Ademais, 8 dos entrevistados informaram que, em média, os projetos desenvolvidos pela organização terminam dentro do prazo previsto, e 2 que os projetos terminam acima do prazo previsto no cronograma. Mais uma vez, houve divergência entre as respostas de membros da mesma entidade. Importante pontuar que, o mesmo pesquisado que não informou o número de pessoas com qualificação em 
GP, respondeu que os projetos da sua entidade terminam acima do prazo previsto no cronograma.

A temática "Custos" foi objeto da seção seguinte. Quando perguntados sobre o nível de detalhe na elaboração do orçamento, todos os pesquisados afirmaram que a organização orça todos os componentes e atividades do projeto.
Além disso, segundo a Figura 4, 5 dos colaboradores declararam que, em média, $100 \%$ do orçamento é executado ao final dos projetos, ou seja, gasta-se o valor inicialmente planejado. Outros 3 afirmaram que se executa abaixo de $100 \%$ do orçamento, isto é, gasta-se menos que o valor estipulado.

\section{Figura 4}

Porcentagem se Utilização do Orçamento ao Final dos Projetos das Organizações
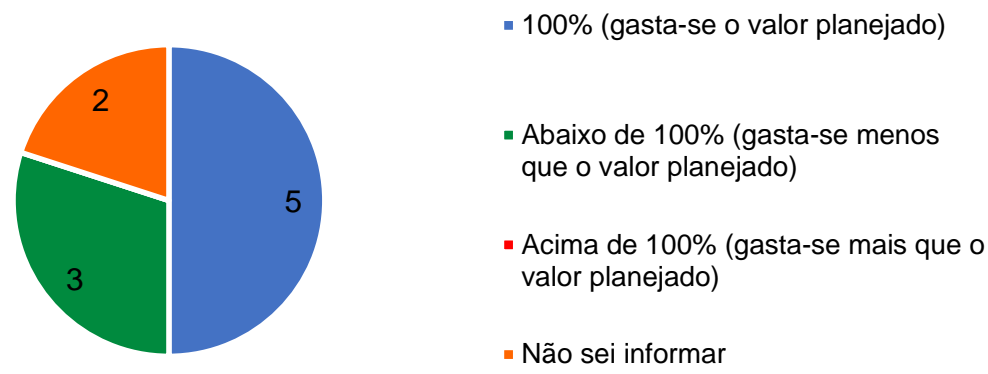

Fonte: Resultados originais da pesquisa.

É um fator extremamente positivo o fato de que 5 dos entrevistados afirmarem que se gasta o valor planejado, além de 2 que declararam que suas instituições gastam abaixo do orçado. Em um cenário de recursos escassos, um bom planejamento de custos, alinhado a uma implementação em consonância com o plano, é um elemento fundamental para uma boa gestão de projetos, e, consequentemente, para a entrega dos resultados esperados.
Outros dois temas de grande importância abordados no questionário foram "Captação de Recursos e Gestão de Parcerias". A análise das respostas gera um alerta ao governo angolano, tendo em vista que, primeiramente, quando questionados sobre as principais origens dos recursos da organização, nenhum pesquisado marcou a opção "governo". Todavia, 9 dos colaboradores marcaram doadores individuais como principais fontes de recursos, seguidos 
de organizações internacionais com 7

indicações, e recursos próprios com 3

(Figura 5).

\section{Figura 5}

Origem dos Recursos das Organizações (Mais de uma Opção Pôde ser Marcada)

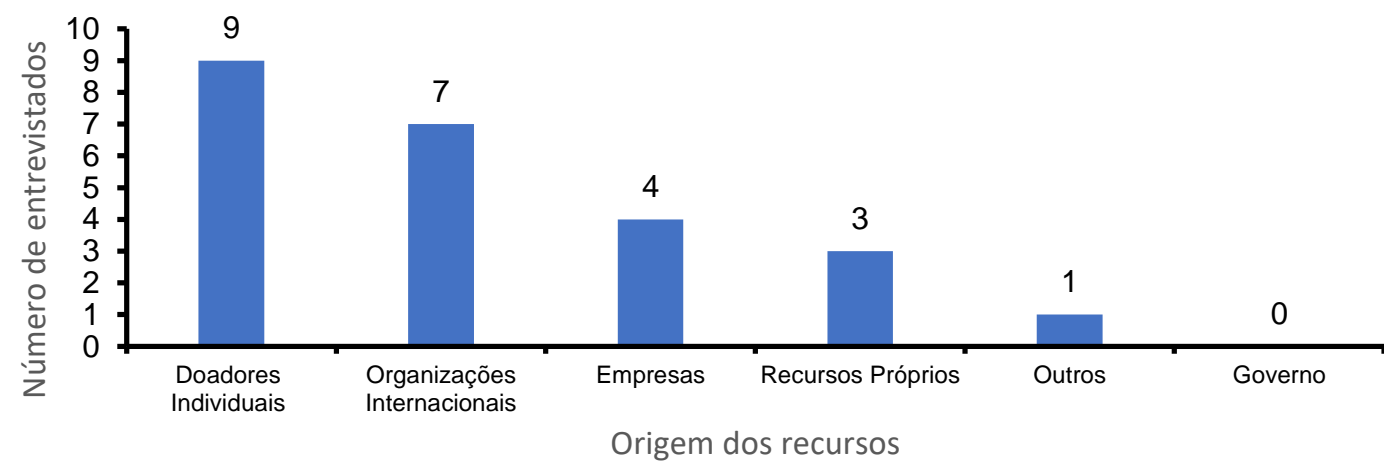

Fonte: Resultados originais da pesquisa.

Conforme será discutido no tópico seguinte, esse é um fator preocupante para a sustentabilidade dessas instituições, visto que a dependência de doadores individuais gera uma instabilidade, especialmente financeira, de grande dimensão. Sendo assim, seria de extrema importância o apoio governamental, que não foi verificado em nenhuma organização, posto que essas atuam prestando serviços públicos diante da ausência do Estado. Todavia, apesar do governo angolano não ser uma fonte de recursos das organizações em análise, essas desenvolvem algum tipo de parceria com o Estado, tendo em vista que, conforme Figura 6, 7 dos pesquisados relataram que o governo é um dos principais parceiros da organização, o que pode representar o início de uma posterior relação mais profunda entre primeiro e terceiro setor 


\section{Figura 6}

Principais Parceiros da Organização (Mais de uma Opção Pôde ser Marcada)

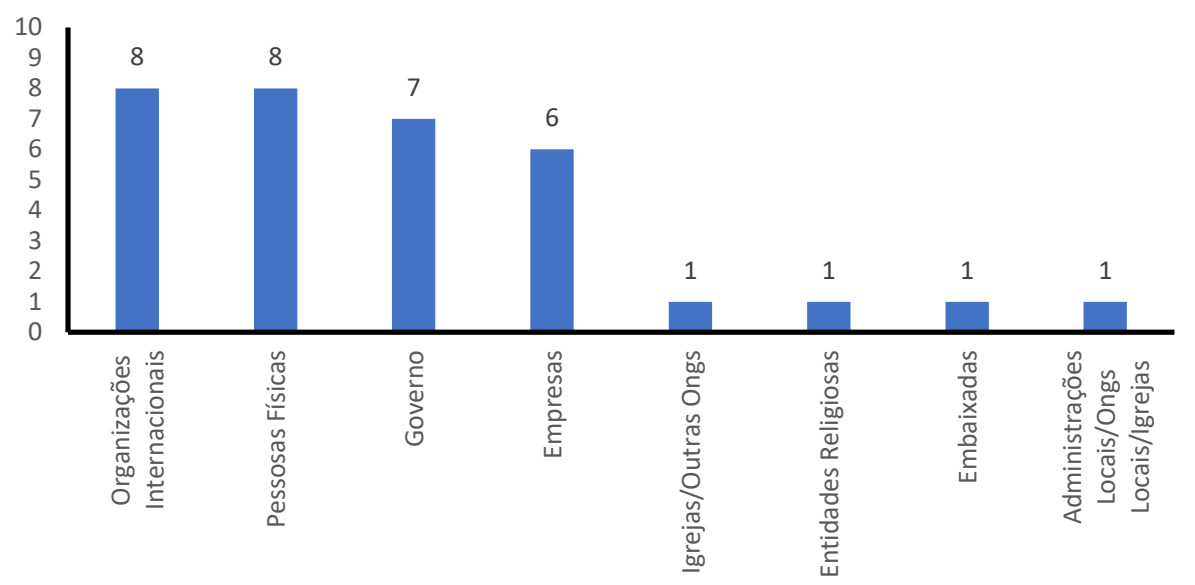

Fonte: Resultados originais da pesquisa

O questionário também abordou durante a execução do projeto, a equipe o tema "Monitoramento e Controle". faz reuniões semanais de Como se pode visualizar na Figura 7, 5 acompanhamento dos trabalhos. Outros dos colaboradores afirmaram que, 3 marcaram que as reuniões são mensais e 2 que essas são realizadas diariamente.

\section{Figura 7}

Frequência das Reuniões de Acompanhamento dos Trabalhos Durante a Execução de

\section{Projeto}
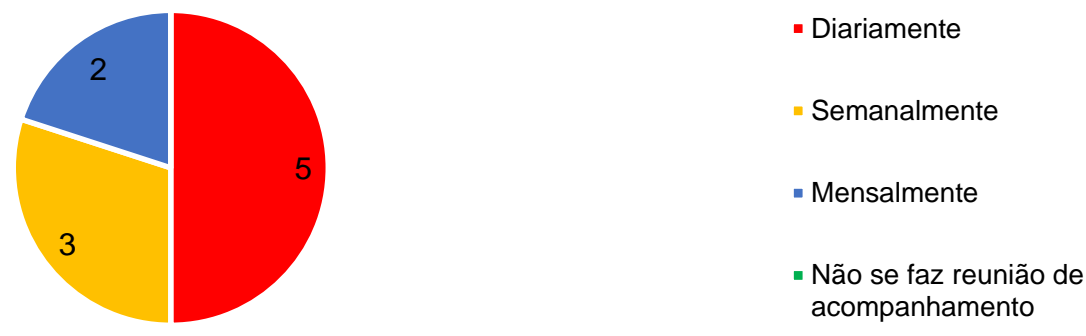

Fonte: Resultados originais da pesquisa

Ainda dentro da temática pesquisados afirmaram que os projetos "monitoramento e controle", 9 dos de suas organizações são monitorados a 
partir de marcos de progresso ou indicadores. $\mathrm{O}$ monitoramento, conforme será explanado no tópico seguinte, é uma etapa fundamental para o cumprimento do escopo do projeto e o seu sucesso final, pelo que o fato de 9 organizações realizarem esse controle mostra algum nível de alinhamento com as boas práticas preconizadas pela gestão de projetos. A última seção tratou de temas gerais dentro da organização.
Questionou-se, primeiramente, quais são os principais desafios enfrentados pela organização para executar os projetos. Dos nove pesquisados que responderam à pergunta, todos marcaram a opção "captação de recursos" como um dos principais desafios, seguida das opções "falta de pessoal qualificado para gerir os projetos" e "número reduzido da equipe", ambas com três votos.

\section{Figura 8}

Principais Desafios Enfrentados Pela Organização Para a Execução dos Projetos (Mais de uma Opção Pôde ser Marcada)

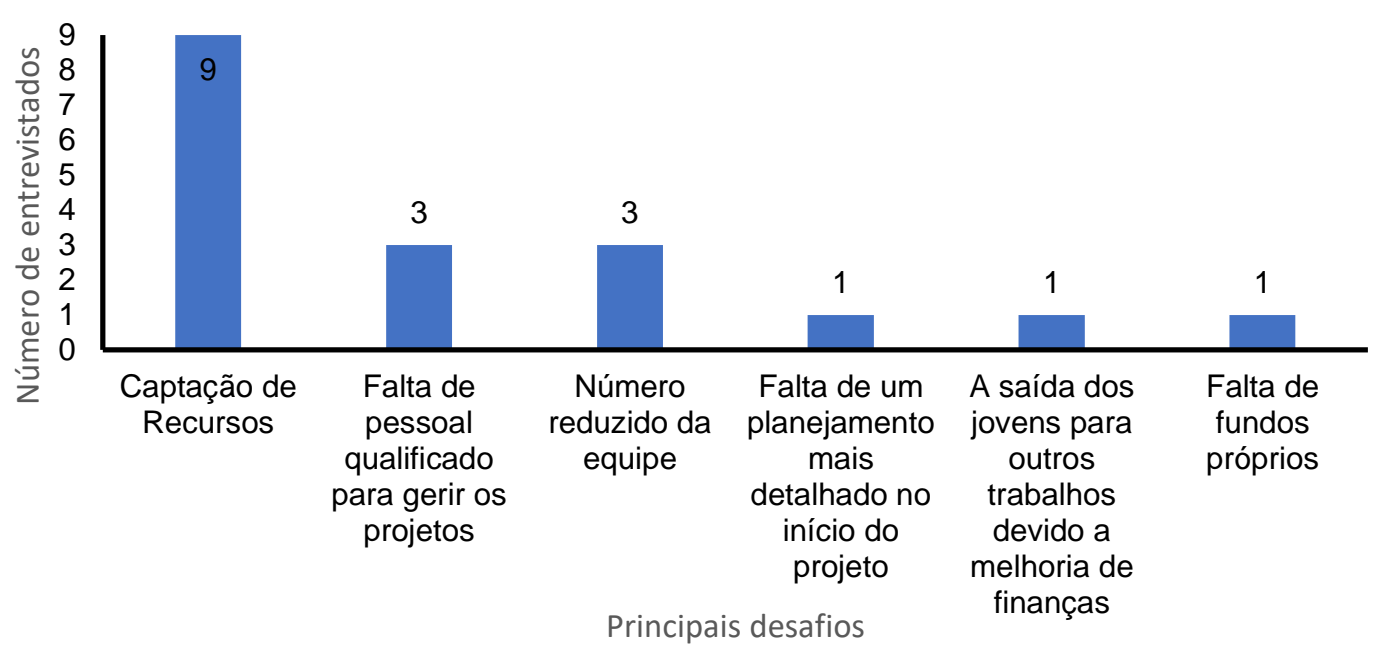

Fonte: Resultados originais da pesquisa.

Por fim, a última pergunta questionou os pesquisados em quais aspectos a organização precisa melhorar. Oito colaboradores, dos nove que responderam à pergunta, afirmaram que a "captação de recurso" é um tema no qual a organização precisa melhorar, em consonância com as respostas dadas à questão anterior, na qual todos marcaram que esse fator também é o principal desafio enfrentado pela organização atualmente. As duas outras opções mais 
marcadas, com cinco votos ambas, foram qualificação da equipe e comunicação com os stakeholders (Figura 9).

A já comentada escassez de recursos que impacta diretamente a estabilidade econômica dessas instituições se mostra uma questão recorrente no âmbito do terceiro setor, consoante será discutido no tópico seguinte, o que demanda ainda mais uma gestão profissionalizada dessas organizações. Ademais, relativamente à qualificação da equipe, pode-se estabelecer uma relação direta entre esse fator e o dado de que uma média de apenas $13 \%$ dos membros das instituições pesquisadas possui conhecimento em gestão de projetos. Por fim, em relação ao desafio sobre a comunicação com os stakeholders, percebe-se que esse encontra relação também com a fraca prestação de contas por parte das organizações, seja pela ausência de sítios eletrônicos oficiais, ou pela pouca profissionalização das redes mantidas, associado ainda a uma não prestação de contas alinhada aos preceitos da gestão de projetos, como será explanado a seguir.

\section{Figura 9}

Aspectos que Precisam ser Melhorados na Organização na Visão do Entrevistado (Mais de uma Opção Pôde ser Marcada)

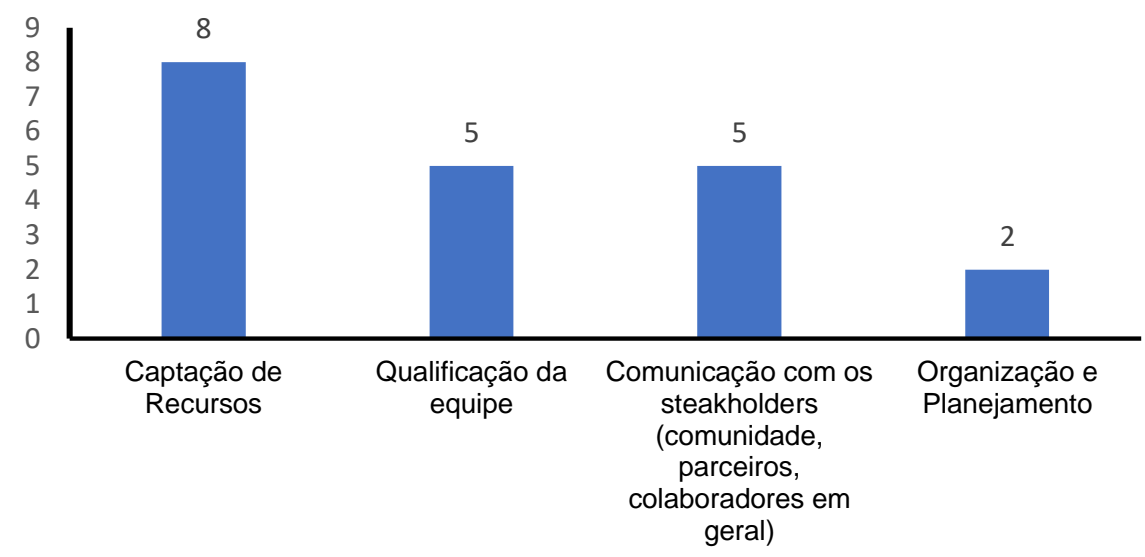

Fonte: Resultados originais da pesquisa

Assim, com base nos resultados expostos, realizou-se a discussão que se segue, fazendo um contraponto constante com a literatura para se 
analisar fundamentadamente a importância da gestão de projetos, especialmente das áreas escolhidas para o desenvolvimento da pesquisa, para o gerenciamento de organizações do terceiro setor, levando em consideração suas peculiaridades e deficiências.

\subsection{Discussão dos resultados}

Primeiramente, a saída da informalidade de Organizações Sociais se deu em Angola a partir da década de 90 com a Lei 14/91 de 11 de maio (Assis, 2015), como anteriormente já relatado, e é coerente com o fato de todas as Organizações pesquisadas terem sido criadas a partir da referida década. Esse fator é de extrema relevância no processo de profisssionalização das ONGs que, por vezes, primam pela informalidade, com poucas normas e procedimentos escritos, o que as leva a agir de forma mais ágil, mas prejudica a gestão, já que as funções e as responsabilidades de seus membros não são determinadas de forma clara (Tenório, 2009).

Relativamente à predominância de atuação nas áreas da educação e da saúde, esse fenômeno parece encontrar conexão com a fraca prestação desses serviços pelo poder público e as deficiências encontradas em ambos os segmentos. Segundo um Relatório da
Organização Mundial de Saúde (OMS) em parceria com o Banco Mundial (BM) divulgado em 2017 (Tracking Universal Health Coverage: 2017 Global Monitoring Report), Angola é o país de língua portuguesa com a porcentagem mais baixa de cobertura de serviços básicos de saúde.

No mesmo sentido, a forte atuação no setor da educação por parte das ONGs ganha contornos ainda mais relevantes quando o Plano de Desenvolvimento Nacional de Angola aponta que a taxa de alfabetização de jovens e adultos angolanos é de $75 \%$ (Ministério da Economia e Planeamento de Angola, 2018). Apesar do avanço conquistado nos últimos anos, visto que no início do século a taxa era de 50\% (Ministério da Economia e Planeamento de Angola, 2018), o país ainda se encontra em uma posição preocupante no Ranking Internacional - posição 132 de 164 países pesquisados-, sendo a média mundial de $86,3 \%$ de pessoas acima de 15 anos que podem ler e escrever (CIA, 2018). Além disso, o documento oficial ainda reconhece que existem crianças fora do sistema de educação, seja por falta de vagas, pela precariedade das estruturas escolares ou ainda por falta de profissionais 
qualificados (Ministério da Economia e Planeamento de Angola, 2018).

Pode-se apontar também uma correlação entre esse dado e a informação já exposta na contextualização de que, segundo o Ministério da Economia e Planeamento (2018), uma das principais causas da pobreza em Angola é à dificuldade de acesso à educação, fazendo sentido o fato de oito dos dez pesquisados terem apontado a educação como um dos segmentos de trabalho das organizações em análise, dada a precariedade da oferta pelo Estado.

O cenário apresentado demonstra a grande importância das atividades desenvolvidas por essas instituições para o crescimento nacional e desenvolvimento de uma sociedade justa e democrática, tendo em vista a função social exercida por essas, necessitando, portanto, que sejam gerenciadas de forma eficiente, transparente $\mathrm{e}$ justa (Nemoto et al., 2018).

Apesar do baixo desempenho nos segmentos citados, o governo angolano tem demonstrado, ao menos no plano estratégico, o conhecimento da necessidade de se priorizar a saúde e a educação. O já citado Plano de Desenvolvimento Nacional 2018-2022, em uma perspectiva de atribuir maior prioridade à dimensão social do desenvolvimento, determinou o aumento gradual da afetação exatamente às funções educação e saúde de $12,4 \%$ até $20 \%$ e de $8,5 \%$ até $15 \%$ da despesa total, respectivamente (Ministério da Economia e Planeamento de Angola, 2018), por se tratar de áreas estratégicas para o desenvolvimento social.

Em relação ao tópico governança, a estrutura de governança exerce uma função extremamente importante no controle das atividades realizadas dentro de qualquer instituição. Segundo Almeida (2015), a governança diz respeito aos "processos e estruturas de controle com fins de mitigar riscos de ineficiência, ou conflitos de agência". Portanto, a governança é uma técnica avançada de gerenciamento, que pode ser aplicada nas mais diferentes organizações, com vistas a garantir uma maior eficiência das tomadas de decisões e a eliminar possíveis conflitos de interesses (Hitt, Ireland \& Hoskisson, 2012).

Pereira (2010) complementa que a governança compreende a estrutura administrativa, política, econômica, social, ambiental, legal e demais outras, que garante que os resultados pretendidos pelas partes interessadas sejam definidos e alcançados através de 
estruturas de decisões e exercício de autoridades definidos. Assim, a existência de uma estrutura de governança detém um papel fundamental dentro de organizações sociais, especialmente, como aponta Garcia (2016), diante do cenário de austeridade vivenciado no dia a dia da gestão dessas instituições, que necessitam de apoio externo constante para a manutenção de suas atividades e devem, portanto, controlar de forma série e eficiente suas ações para uma melhor prestação de contas aos stakeholders.

No que toca ao número de membros por organização, não obstante a informação de um número razoável de membros fixos por entidade, segundo Keleckaite e Meiliene

(2015),

Organizações Não Governamentais lidam constantemente com uma instabilidade no número de funcionários, além da incerteza financeira, que normalmente é deficitária, comprovando a elevada complexidade de projetos sociais.

Contudo, o cenário encontradosobre a quantidade de membros remunerados se revela positivo, tendo em vista a parcela significativa de colaboradores com remuneração. Um dos grandes desafios encontrados no Terceiro Setor recai justamente sobre a remuneração do pessoal, já que se faz necessário equilibrara escassez de recursos com a eficiência, a melhora na qualidade dos serviços, inserir e aperfeiçoar tecnologias, remunerar especialistas, atrair e manter pessoal, entre outros obstáculos que se apresentam regularmente (Bose \& Schoenmaker, 2006). Pedrosa et al. (2009) colabora com esse entendimento afirmando que captar, desenvolver e reter profissionais competentes e alinhados com as estratégias da instituição ainda se caracteriza como um enorme desafio para a maioria das organizações.

Outro fator importante que se comunica diretamente com a remuneração e, consequentemente, com a produtividade, é a motivação. Segundo Bose e Schoenmaker (2006), a falta de remuneração financeira é correlacionada a níveis inferiores de entrega quando se fala da categoria voluntários. Dessa forma, manter uma equipe remunerada de forma justa é um fator que influencia na entrega dos resultados, sendo um meio estratégico de valorizar pessoas, conscientizando-as do valor da sua colaboração para a organização e de que seu trabalho é relevante para que a 
entidade alcance os objetivos propostos (Bose \& Schoenmaker, 2006).

Além disso, outro tema analisado foi o "Conhecimento geral em Gestão de Projetos" por parte dos membros das organizações em estudo. A importância da profissionalização das ONGs com a adoção das boas práticas para o gerenciamento de projetos já é um tema discutido no meio acadêmico (Nemoto $e t$ al., 2018; Bose \&Schoenmaker, 2006). De acordo com Nemoto et al. (2018), a ausência de uma metodologia de gestão de projetos ou o uso inadequado de ferramentas de gerenciamento foi elencada pelo The Standish Group (2010) como um dos dez fatores que mais concorrem para $\mathrm{o}$ insucesso de projetos. Bose e Schoenmaker (2006), corroborando com o estudo supracitado, apontam que muitos são os desafios corriqueiramente enfrentados pelas organizações sociais e quase todos perpassam pela temática da capacidade gerencial.

Nemoto et al. (2018) ainda aduz que $\mathrm{o}$ fator fundamental que gera a eficácia dos resultados esperados de um projeto é o planejamento, isto é, o emprego de ferramentas/metodologias e a seleção de um conjunto de estratégias mais adequadas ao meio organizacional. Todavia, durante muitos anos, existiu uma mentalidade entre gestores de ONGs de que o vínculo do indivíduo com os objetivos da organização eram mais que suficientes para $o$ comprometimento com o trabalho (Bose \& Schoenmaker 2006), gerando um caráter pouco profissional da gestão de recursos humanos das entidades sociais, que eram fortemente influenciadas por aspectos ideológicos (Fischer, 2004).

Portanto, visualizar um quadro no qual metade das ONGs em análise possuem um Gestor de Projetos realizando o gerenciamento diário de suas atividades, bem como 5 dos entrevistados afirmam deter um nível avançado na área em questão, pode revelar uma certa maturidade organizacional no que tange $o$ conhecimento em Gestão de Projetos (GP). Ademais, 8 dos pesquisados informaram possuir algum tipo de formação ou treinamento na área de "Gestão de Projetos".

$\mathrm{Na}$ temática escopo, segundo o PMI (2017), a especificação do escopo é a definição dos objetivos do projeto, das entregas principais, das premissas e das restrições, no qual se documenta tanto o escopo do projeto como o do produto e se descreve detalhadamente as entregas, promovendo um consenso do escopo entre os stakeholders. Campos (2012) 
afirma que, no que tange a concepção e administração de projetos em geral, é necessário estabelecer determinados marcos e, consequentemente, acompanhá-los, pois orientações claras, acompanhadas e devidamente monitoradas geram resultados consensuais. Um desses marcos é exatamente o escopo controlado, sendo função do gerenciamento do escopo estabelecer especificamente o trabalho a ser realizado por cada agente do projeto (Campos, 2012).

Já a EAP é uma decomposição hierárquica de todo o trabalho a ser realizado pela equipe do projeto com a finalidade de alcançar os objetivos desse e gerar os resultados esperados (PMI, 2019). Trata-se do desmembramento do projeto em componentes e partes menores que sejam melhor gerenciáveis (Campos, 2012).

Bonfim et al. (2012) aponta que o elemento "especificação" é frequentemente desprezado em detrimento da observância dos prazos e do orçamento do projeto. Todavia, uma descrição do escopo bem elaborada propicia a realização de um planejamento mais detalhado por parte da equipe, orientando o trabalho dessa ao longo de toda a execução, e ainda produz a linha de base com vistas a aferir se eventuais solicitações de mudança ou trabalho extra fazem parte do escopo ou estão fora dos objetivos do projeto (PMI, 2019). Apesar da divergência encontrada nas respostas, pode-se inferir que todas as organizações utilizam meios para garantir que o escopo do projeto seja definido corretamente, o que, segundo os supracitados autores, possibilita uma maior probabilidade de a organização alcançar os resultados desejados no encerramento. Ademais, o escopo precisa estar claro, pois custos e tempo dependem de um escopo bem definido (Bonfim et al., 2012).

Outra área chave para o gerenciamento e que foi analisada na presente pesquisa é o cronograma, tema que, segundo os entrevistados, recebe atenção das organizações, tendo em vista o fato de os 9 entrevistados terem respondido positivamente à pergunta se a organização elabora ou não um cronograma. Maximiano (2014) descreve que o cronograma é uma representação gráfica da divisão das atividades ao longo de um lapso temporal pré-determinado, sendo um retrato da programação do projeto, baseado em um planejamento definido pela equipe. Resumidamente, é o processo pelo qual se associa o trabalho a ser executado ao decorrer do tempo 
(Maximiano, 2014). Segundo o PMI (2017), o cronograma do projeto apresenta um planejamento minucioso de como e quando se darão as entregas do projeto, servindo como instrumento de comunicação, gestão de expectativas dos stakeholders e fundamento para a elaboração de relatórios de desempenho. Portanto, se mostra em consonância com os resultados esperados com a utilização das boas práticas de gestão de projetos o fato de 8 dos entrevistados afirmarem que os projetos de suas instituiçõos terminam dentro do prazo previsto.

A gestão do tempo do projeto compreende todos os elementos indispensáveis para o gerenciamento do término do projeto no prazo previsto (Bonfim et al., 2012), o que impacta de forma direta diversas outras áreas da gestão de projetos e, consequentemente, o sucesso do projeto como um todo. Por exemplo, prazos e custos estão intrinsicamente ligados, tendo em vista que, se o projeto tem um aporte de recursos maior, o prazo diminui, no entanto, o custo aumenta (Maximiano, 2014). Além disso, para realizar qualquer atividade prevista no cronograma, utiliza-se recursos; esses, além da mão de obra, custam dinheiro (Maximiano, 2014).
A gestão dos custos do projeto engloba estimar, orçar e controlar os custos de forma a possibilitar que o projeto seja concluído no limite do orçamento aprovado, preocupando-se primordialmente com os custos dos recursos essenciais para executar as atividades do projeto (Bonfim et al., 2012), processo que, segundo os entrevistados, é realizado por todas as organizações. Segundo o PMI (2017), o orçamento do projeto inclui todos os valores aprovados para a execução do projeto. Assim, a gestão de projetos se mostra substancial no empenho para alcançar o escopo, respeitar os prazos e os custos, propiciando ainda a capacidade de detecção e controle dos custos e prazos, com vistas a manter a competividade e superar as expectativas das partes interessadas (Bonfim et al., 2012).

Importante salientar também que a existência de organizações do terceiro setor não desresponsabiliza o Estado de suas funções, mas deve possibilitar o estabelecimento de parcerias com este, com vistas a mobilizar recursos, valorizar e perceber que não se constrói uma sociedade justa sem a participação popular (Cardoso, 2004). Segundo Conceição e Silva (2019), gestão financeira se constitui um dos principais 
problemas do setor, porque, mesmo que essas organizações não visem o lucro, os projetos desenvolvidos que possuem o intuito de beneficiar a comunidade precisam de recursos financeiros, sendo estes oriundos de pessoas físicas e/ou jurídicas e do governo. Portanto, o fato de nenhuma das organizações pesquisadas receber apoio financeiro estatal demonstra uma falha nesse processo e pode representar uma ameaça à sustentabilidade dos projetos sociais desenvolvidos.

Segundo Valadão Júnior et al. (2008), a sustentabilidade se fundamenta no tripé sustentabilidade econômica, sustentabilidade social e sustentabilidade cultural, isto é, se faz necessário assegurar que a organização possua viabilidade econômica, fundamentada em ações coerentes à solução dos problemas combatidos, garantindo, assim, a eficácia da resposta social desejada. Ademais, Cardoso (2004) afirma que quando governo e sociedade trabalham em conjunto é possível realizar operações com um menor custo e uma maior eficácia, e, o mais relevante, o fato dessa parceria gerar um maior envolvimento dos destinatários dessas ações.

Cabe frisar também que outra característica que chamou atenção e que impacta diretamente na sustentabilidade foi a falta de diversificação de financiamento. Tamanha é a importância do tema variabilidade de financiamento que, segundo Carvalho e Felizola (2009), a capacidade de compreender e desenvolver todos os meios à disposição para obter recursos, de forma a possuílos em montante satisfatório, continuamente e sem dependência ou submissão a qualquer fonte específica de financiamento é uma das habilidades mais essenciais para o gestor de projetos do terceiro setor.

Segundo Carrilho (2008), parceria pode ser definida como uma interação negocial, com diferentes graus de (in)formalidade, composta por agentes com traços distintos e interesses em comum, o que pressupõe o compartilhamento dos benefícios em potencial, bem como dos riscos, e a coesão entre os parceiros, durante todo o processo, com rearranjo das respectivas relações. Portanto, apesar da ausência de repasse financeiro, uma parcela das ONGs atuam em parceria com o Governo, seja por intermédio de apoio técnico, seja por meio da promoção da legitimidade da organização ou das outras mais diversas formas possíveis de se promover colaboração. 
Sobre monitoramento e controle, de acordo com Oliveira, Ross e Altimeyer (2005), o processo de monitoramento e controle se remete ao processo de validação efetuado ao longo da execução do projeto, na proporção em que se procura entender e medir se o que foi planejado condiz com a realidade. $\mathrm{O}$ PMI (2017) aduz que é o processo pelo qual se faz o acompanhamento, se analisa e se relata o progresso geral do projeto com a finalidade de garantir a observância dos objetivos definidos no processo de planejamento. Todavia, cabe esclarecer que a reunião é apenas uma das ferramentas utilizadas para realizar esse controle. Além dessa, o PMI (2017) elenca como ferramentas e técnicas do processo "monitoramento e controle" à opinião especializada a análise de dados e a tomada de decisões. No que tange especificamente às reuniões, essas podem se dar de forma presencial, virtual, formal ou informal, podendo contar com a participação de membros da equipe e outros stakeholders do projeto.

Assim, analisando a importância desse monitoramento, Calil e Ehlers (2004) sinalizam que adotar medidas de monitoramento e de avaliação favorecem os processos de aprendizagem tanto individual como coletivo. Ademais, os autores sustentam que a capacidade de aprendizagem é um meio crucial para se desenvolver o fortalecimento das organizações sociais, pois é por intermédio da aplicação dessas ferramentas de monitoramento que se torna viável estimular aprendizados individuais e coletivos, que terão reflexos diretos na gestão (Calil e Ehlers, 2004). Por fim, o PMI (2017) defende que os benefícios centrais do processo em análise são possibilitar que as partes interessadas compreendam como o projeto se encontra atualmente, tenham a capacidade de reconhecer as ações necessárias para tratar qualquer problema, bem como a previsibilidade acerca do cenário futuro do projeto, prevendo custos e prazos.

$\mathrm{Na}$ seção final acerca dos principais desafios enfrentados pela organização para a execução dos projetos, a opção unanimemente marcada foi captação de recursos. Essas respostas por parte dos entrevistados estão em consonância com a pesquisa de Carvalho e Felizola (2009) que afirmam que o processo de captação de recursos se mostra como um dos desafios centrais da gestão dessas entidades, tendo em vista a necessidade de se alcançar a sustentabilidade dos projetos. 
Ademais, conforme apontam Cruz e Estraviz (2000), desenvolver uma profissionalização da gestão de entidades não governamentais demanda um processo de estruturação do segmento de captação de recursos, já que, ao que parece, vive-se uma crise de sustentabilidade no terceiro setor e, se um dia existiu segurança de recursos continuados, isso ficou no passado (Carvalho \& Felizola, 2009). Assim, na busca de vencer essa crise de sustentabilidade e garantir que os recursos visados sejam captados, bem como, consequentemente, possibilitar a viabilidade dos projetos, várias são as estratégias necessárias (Silveira et al., 2006), e uma delas passa pela utilização do marketing social. Segundo Carvalho e Felizola (2009), o marketing pode contribuir para tornar as organizações mais eficientes em diversas áreas, propiciando diagnóstico de atuação; ampliando a captação de recursos; favorecendo a identificação de oportunidades e novas formas de ação social; facilitando o estabelecimento de parcerias com os demais setores.

Ainda segundo os autores supracitados (Carvalho \& Felizola, 2009), o marketing favorece o processo social pelo qual os indivíduos se encontram e fazem uso das oportunidades para revelarem suas necessidades e seus produtos de valor com a finalidade de supri-las. Em consonância com esse entendimento, Silveira et al. (2006) afirma que, da mesma forma que as empresas fazem uso do marketing como estratégia corporativa, as organizações do terceiro setor podem se valer da comunicação com diversas finalidades: buscar novos parceiros e financiadores, repassar informações a conselheiros e outras partes interessadas sobre a execução do projeto, selecionar voluntários, gerar maior engajamento dos destinatários das ações, realizar prestação de contas à sociedade de todos os recursos recebidos e como foram aplicados, dentre tantos outros.

Valadão Júnior et al. (2008) defende que a capacidade de se constituir e de se projetar na esfera pública com protagonismo, seja utilizando alguma mídia, no relacionamento com a sociedade, e/ou por intermédio de parcerias com o governo, com instituições privadas e outros setores, aparenta se configurar como premissa para a sustentabilidade dos projetos desenvolvidos no âmbito de organizações do Terceiro Setor.

Essa temática se correlaciona com a necessidade de as organizações 
manterem, ao menos, sítios institucionais bem atualizados, com informações robustas e prestações de contas completas, como anteriormente pontuado na análise da seção "Governança", que se conectou também com a seção "Captação de Recursos e Gestão de Parcerias", mostrando a interdisciplinaridade das áreas em Gestão de Projetos, e como se faz necessário que o Gestor possua uma visão holística na realização do seu trabalho.

Assim, conforme mencionado por Valadão Júnior et al. (2008), a estabilidade e continuidade dos projetos de organizações do Terceiro Setor parece demandar uma transformação institucional tanto no que diz respeito a adoção de novas metodologias/práticas de gerenciamento de projetos quanto a uma nova visão de parcerias e articulações que expandam o alcance social e a legitimidade dessas instituições.

Por fim, no trabalho de Nemoto, Silva e Pinochet (2018), que buscou analisar 5 ONGs brasileiras, foi verificado que as gestoras possuem um nível razoável de conhecimento das boas práticas na gestão de projetos, embora muitas vezes não estejam cientes disso. Nesse sentido, assim como no trabalho citado, foi possível identificar que, apesar de serem identificados pontos de melhoria e aprimoramento, as 4 áreas de conhecimento em gestão de projetos escolhidas para o presente trabalho são de alguma forma contempladas no gerenciamento de todas as instituições em análise.

\section{Conclusões}

As análises apresentadas quanto à gestão de projetos no terceiro setor angolano, relativamente às 6 ONGs em estudo, revelam um panorama de aplicação de parcela das boas práticas em gestão de projetos preconizados pelo PMI. Importante salientar primeiramente que, a pesquisa se ateve a apenas 4 das áreas de conhecimento previstas no PMBOK, quais sejam, escopo, custos, tempo e stakeholders. Segundo que, o questionário contou com 2 ou 3 perguntas por área, abordando as ferramentas e técnicas mais básicas para a realização de um gerenciamento de projetos à luz do PMBOK. Portanto, tendo em vista a limitação dos dados colhidos, não é possível analisar em profundidade o nível de adequação do gerenciamento de projetos dessas organizações com a práticas mais atuais propostas pelo PMI. 
Apesar das limitações apresentadas, foi possível verificar que, de acordo com as respostas dos respectivos membros, as 4 áreas de conhecimento em gestão de projetos escolhidas para o presente trabalho são de alguma forma contempladas no gerenciamento de todas as instituições em análise. Algumas com um nível maior de detalhamento nos processos citados, outras numa perspectiva mais inaugural e distante da complexidade dos processos previstos pelo PMI. Especialmente em relação ao gerenciamento dos stakeholders, notouse uma fraca aplicação da gestão de projetos no que toca à prestação de contas para as partes interessadas, tendo em vista a falta de uma maior transparência quanto à condução dos projetos, seja em termos econômicos ou de resultados. Ademais, a pesquisa mostrou um quadro de profissionalismo na atuação dessas entidades que começa desde a constituição formal como organizações não governamentais dentro dos parâmetros legais angolanos até à aplicação de preceitos básicos da gestão de projetos, fator este de extrema importância para o sucesso dos projetos conforme pontuado ao longo da discussão dos resultados. Foram encontrados resultados positivos em relação ao escopo, com a maioria das ONGs informando elaboram documentos como Especificação do Escopo ou um Termo de Referência, bem como uma Estrutura Analítica do Projeto (EAP). Além disso, as ONGs parecem terminar dentro do prazo previsto seus projetos desenvolvidos.

Contudo, apesar do cenário favorável a algumas áreas da gestão de projetos, muitos são os desafios enfrentados pelo terceiro setor angolano e que, por vezes, estão ligados a uma aplicação ainda deficitária da temática em questão. Um dos resultados que demonstram isso é que, quando questionados em quais aspectos a organização precisa melhorar, cinco dos dez entrevistados afirmaram que a qualificação da equipe era um deles, o que corrobora com a análise de que um percentual ainda baixo das equipes possui conhecimento/treinamento em gestão de projetos. Todavia, o principal desafio apontado foi a captação de recursos, dilema comum ao terceiro setor, o que ressalta ainda mais a importância da utilização das melhores práticas em gestão de projetos, posto que a literatura mostra como é possível impulsionar e garantir uma maior sustentabilidade de projetos por meio da aplicação de ferramentas e práticas 
corretas. Por fim, uma oportunidade de pesquisa futura na temática em questão seria um estudo quantitativo do terceiro setor angolano, com vistas a verificar, a partir de uma análise amostral

\section{Referências}

Assis, J. (2015). Práticas sociais e políticas das ONGs em Angola. Metodologias e relações de poder: O caso da ADRA e da Visão Mundial. Mulemba, (5 (10), 261-288. doi: https://doi.org/10.4000/mulemba .2037

Bomfin, D. F, Nunes, P., \& Hastenreiter, F. (2012). Gerenciamento de Projetos Segundo o Guia PMBOK: Desafios para os Gestores. Revista De Gestão E Projetos, 3(3), 58-87. doi: https://doi.org/10.5585/gep.v3i3. 78

Bose, M., \& Schoenmaker, L. (2006). Especificidades da gestão de pessoas no terceiro setor. Revista Eletrônica De Ciências Administrativas, 5(2), 1-16. doi: https://doi.org/10.5329/recadm.2 0060502004

Ehlers, E. M., \& Calil, L. P. (2004). Monitoramento e avaliação: uma oportunidade de aprendizagem. In: Voltolini, R (Org.) Terceiro setor: planejamento e gestão, 2, 103-120. São Paulo: Editora Senac.

Campos, L. F. R. (2012). Gestão de Projetos. Curitiba-PR: Instituto Federal Paraná. significativa, o perfil de gerenciamento de projetos dessas organizações e se alguns dos resultados encontrados nesta pesquisa se constituem como um padrão do setor.

Cardoso, R. (2004). Sustentabilidade, o desafio das políticas sociais no século 21. São Paulo em perspectiva, 18(2), 42-48. doi: https://doi.org/10.1590/S010288392004000200005

Carrilho, T. (2008). Conceito de parceria: três projectos locais de promoção do emprego. Análise Social, 81-107.

Carvalho, C. M. S., \& Felizola, M. P. M. (2009). A importância do marketing na captação de recursos para o terceiro setor. In UNIT-Universidade Tiradentes (SE). Intercom-Sociedade Brasileira de Estudos Interdisciplinares da Comunicação. XI Congresso de Ciências da Comunicação na Região Centro-Oeste, Brasília/DF (pp. 4-6).

Central Intelligence Agency (CIA). 2018. The World Factbook.

Disponível em: https://www.cia.gov/library/publ ications/resources/the-worldfactbook/fields/370.html Acesso em: 17 jun. 2020.

Conceição, A. F., \& Silva, A. P. H. (2019). Project Management and Resource Management in The Third Sector: The Case of TV OVO. Brazilian Journal of 
Management \& Innovation, 7(1), 24-44.

Cruz, C. M., \& Estraviz, M. (2000).

Captaçäo de diferentes recursos para organizaçöes sem fins lucrativos. In: Captaçäo de diferentes recursos para organizaçöes sem fins lucrativos. (pp. 158-158).

Garcia, Cláudia Maria Serpa (2016) Governança: uma estratégia para o terceiro setor face ao contexto de austeridade. Revista de Psicologia da Criança e do Adolescente. ISSN 1647-4120. 7:1-2 (jan.-dez. 2016) 171-191.

Gil, A. (2018). Como elaborar projetos de pesquisa. São Paulo: Atlas.

Hernandez, Y., \& Cormican, K. (2016). Towards the effective management of social innovation projects: Insights from project management. Procedia Computer Science, 100, 237-243.

Hitt, M. A.; Ireland, R. D.; Hoskisson, R. E. (2012). Strategic management cases: competitiveness and globalization. California: Cengage Learning.

Instituto Nacional de Estatística (INE). 2019. Folha de Informação rápida IEA. Disponível em: https://www.ine.gov.ao/. Acesso em: 17 jan. 2020.

Jha, K. N., \& Iyer, K. C. (2006). Critical determinants of project coordination. International Journal of Project Management, 24(4), 314-322. doi: https://doi.org/10.1016/j. ijproman.2005.11.005.

Keleckaite, M., \& Meiliene, E. (2015). A importância das metodologias e ferramentas de gestão de projetos em organizações não governamentais: estudo de caso da Lituânia e da Alemanha. PM World Journal, 4 (7), 1-17.

Maximiano, A. C. A. (2014).

Administração de projetos: como transformar ideias em resultados. São Paulo: Atlas.

Mendonça, L. R. de, \& Machado Filho, C. A. P. (2004). Governança nas organizações do terceiro setor: considerações teóricas. Revista de Administração da Universidade de São Paulo, 39(4).

Ministério da Economia e Planeamento. 2018. Plano de Desenvolvimento Nacional 2018-2022. Disponível em:

http://www.mep.gov.ao/VerPubl icacao. aspx? $\mathrm{id}=1590$. Acesso em: 17 jan. 2020.

Ministério da Economia e Planeamento. 2019. Aproveitar o potencial da juventude para colher o dividendo demográfico em Angola. Luanda, Angola. Disponível em: https://www.afidep.org/publicati on/aproveitar-o-potencial-dajuventude-para-colher-odividendo-demografico-emangola/ Acesso em: 17 jan. 2020.

Nemoto, M. C. O., Silva, D. A., \& Pinochet, L. H. C. (2018). Avaliação de aplicações das boas práticas na gestão de 
projetos sociais para instituições do terceiro setor. Revista de Gestão e Projetos, 9(3), 67-80.

OGC (Office of Government

Commerce). (2009). Managing

Successful Projects with PRINCE2. United Kingdom: The Stationary Office.

Oliveira, B., Ross, E. S., \& Altimeyer, H. Y. (2005). Proposta de um modelo de planejamento estratégico para instituições sem fins lucrativos. Revista da FAE, 8(1), 69-80.

Pedrosa, A. C. G., Cabral, A. C., Pessoa, M. N. M., Parente, T. C., Penha, E. D. S., \& Alves, R. A. (2009). Competência gerencial no terceiro setor: um estudo em Organizações Não Governamentais na cidade de Fortaleza-Ceará. In: XXXIII Encontro da ANPAD. São Paulo/SP.

Pereira, R.S.; Moraes, F.C.C.; Mattos Junior, A.B.; Palmisano, A. (2013). Especificidades da Gestão no Terceiro Setor. Revista Organizações em Contexto. 9(18): 167-195.

Prado, D. (2016). Maturidade em gerenciamento de projetos (Vol. 7). Nova Lima: Falconi Editora.

Programas das Nações Unidas para o Desenvolvimento (PNUD). (2018). Relatório de Desenvolvimento Humano. Disponível em: https://www.br.undp.org/content /brazil/pt/home/library/idh/relato rios-de-desenvolvimentohumano/relatorio-dodesenvolvimento-humano- 2018.html. Acesso em: 17 jan. 2020.

PMI - Project Management Institute. (2017). Um guia do conhecimento em gerenciamento de projetos [Guia PMBOK]. Newtown Square, PA: Project Management Institute.

Ribeiro, B. A. (2011). Os passos metodológicos para a elaboração de projetos sociais. Conexão ciência (Online), 5(1), 11-22.

Silva, L. B. C. (2017). GESTÃO DE PROJETOS NO TERCEIRO SETOR: Estudo de caso da ONG GACC em São Luís-MA. Monografia de graduação. Universidade Federal do Maranhão, São Luís, MA, Brasil.

Silveira, R. B. da, de Souza Campos, L. M., \& Marcon, R. (2006). A segmentação e a promoção na captação de recursos: um estudo em fundações do terceiro setor. Revista de Administração FACES Journal.

Siqueira, L. D., Crispim, S. F., \& Gaspar, M. A. (2017). A influência do escritório de projetos e da estrutura organizacional projetizada no alinhamento dos projetos de tecnologia da informação aos modelos de negócios. Revista Gestão \& Tecnologia, 17(2), 6692. doi: https://doi.org/10.20397/21776652/2017.v17i2.1132

Tenório, F. G. (2015). Gestão de ONGs: principais funções gerenciais. Rio de Janeiro: Editora FGV. 
The Standish Group. (2010). Chaos

Summary for 2010. The Standish Group, Boston, MA.

Tuzzo, S. A., \& Braga, C. F. (2016). O processo de triangulação da pesquisa qualitativa: 0 metafenômeno como gênese. Revista Pesquisa Qualitativa, 4(5), 140-158.

Valadão, V. M., Malaquias, R. F., \& de Sousa, E. G. (2008).

Controladoria como uma opção à sustentabilidade econômica nas organizações de Terceiro Setor: o caso de uma associação.
Revista Contemporânea de Contabilidade, 5(9), 131-152.

Vargas, R. V. (2005). Gerenciamentode projetos: estabelecendo diferenciais competitivos. Rio de Janeiro: Brasport.

World Health Organization (WHO) (2017). Tracking universal health coverage: 2017 Global Monitoring Report. Disponível em:

https://apps.who.int/iris/bitstrea $\mathrm{m} /$ handle/10665/259817/978924 1513555-eng.pdf. Acesso em: 03 mai. 2021. 